\title{
NEITHER VEGETATIVE NOR REPRODUCTIVE ADVANTAGES ACCOUNT FOR HIGH FREQUENCY OF MALE-STERILES IN SOUTHERN SPANISH GYNODIOECIOUS DAPHNE LAUREOLA (THYMELAEACEAE) ${ }^{1}$
}

\author{
Conchita Alonso and Carlos M. Herrera²
}

Estación Biológica de Doñana, Consejo Superior de Investigaciones Científicas, Apartado 1056, E-41080 Sevilla, Spain

\begin{abstract}
In gynodioecious species, male-steriles (termed "females" hereafter) usually exhibit some reproductive advantage over hermaphrodites that allow them to compensate for the loss of male reproductive function. This compensation can result from higher fecundity, vegetative outperformance, and/or lower inbreeding depression. In this study we compared vegetative and reproductive parameters of female and hermaphrodite Daphne laureola individuals in two southeastern Spanish populations and estimated the magnitude of inbreeding depression up to the seedling emergence stage by conducting controlled pollinations and experimental sowings of seed progenies in the field. Reproductive shrubs of both sexes did not differ significantly in size, leaf production, leaf size, leaf growth, nutrient allocation to leaves, and production of flowers and fruits. Seed set and seed size of cross- and self-pollinated flowers of hermaphrodites and cross-pollinated females were also similar. Seedling emergence rates of self- and cross-pollinated seeds from hermaphrodites under natural field conditions were similar, suggesting a minor role of inbreeding depression up to that reproductive stage. Seeds from females produced more seedlings than selfed seeds from hermaphrodites. In 21 populations surveyed in the study region over a broad geographical and elevational gradient, the proportion of females ranged between 20.6 and $56.1 \%$ and was inversely related to elevation. The establishment and maintenance of females in southeastern Spanish populations of D. laureola seem to be mainly mediated by ecological factors.
\end{abstract}

Key words: altitudinal gradient; Daphne laureola; gynodioecy; inbreeding depression; sex ratio; sexual dimorphism; Thymelaeaceae.

Sexually dimorphic plant populations ordinarily exhibit gender-related variation involving one or more morphological, ecological, life-history, or reproductive attributes. Among dioecious plants, for example, male and female individuals may differ in a broad variety of aspects, including phenology, susceptibility to herbivores, microhabitat selection, physiology, pollinator composition, biomass and resource allocation, and growth patterns (Ågren et al., 1999; Dawson and Geber, 1999; Delph, 1999; and references therein). In gynodioecious species, in contrast, differences between female and hermaphrodite individuals commonly involve one or more fecundity-related components, such as flower production (e.g., Krohne, Baker, and Baker, 1980; del Castillo, 1993; Maki, 1996), fruit set (e.g., Shykoff, 1988; Delph and Lloyd, 1991; Hermanutz and Innes, 1994), fruit and seed production (e.g., Kohn, 1989; Ågren and Willson, 1991; Jordano, 1993; Wolfe and Shmida, 1997), fruit seediness (e.g., Stevens, 1988; Ågren and Willson, 1991), and size and resource allocation patterns (e.g., Ashman, 1992a, 1994, 1999; Delph, 1993; Maki, 1996; Wolfe and Shmida, 1997). Dimorphism in other aspects, such as phenology (Webb, 1976; Ågren and Willson, 1991) or floral nectar production (Uno, 1982; Ashman and Stanton, 1991; Delph and Lively, 1992), has been reported less frequently.

\footnotetext{
1 Manuscript received 30 June 2000; revision accepted 13 October 2000.

The authors thank Manolo Carrión, Alicia Prieto, Dori Ramírez, Rocío Requerey, and Antonio Rodríguez for their assistance in the field and the laboratory; Asunción Castro, Carmen Mazuelo, and their colleagues at IRNAS lab for conducting the chemical analyses of leaves; and Gonzalo Nieto for useful advice. This research was supported by grants PB91-0114 (DGICYT) and PB96-0856 (DGES) to CMH and a predoctoral (MEC) fellowship to CA. While writing this paper CA was supported by an European Commission Marie-Curie fellowship (ERBFMBICT-983034).

${ }^{2}$ Author for reprint requests (e-mail: herrera@cica.es, Fax: + 34954 621125).
}

The prevalence of fecundity-related dimorphism in gynodioecious plants and the fecundity advantage generally exhibited by female individuals are both consistent with theoretical models for the maintenance of female individuals in gynodioecious populations, according to which female plants must incur some compensatory fitness advantage that cancels its gametic disadvantage relative to hermaphrodite conspecifics (Lewis, 1941; Lloyd, 1976; Gouyon and Couvet, 1987). However, a number of exceptions to the rule of female advantage exist (e.g., Uno, 1982; van Damme, 1984; Stevens, 1988; Kohn, 1989; Slade and Hutchings, 1989; del Castillo, 1993; Dinnetz and Jerling, 1997; Williams and Fenster, 1998), which clearly indicates that gender-related differences in fecundity alone cannot account for the maintenance of females in all species. Inbreeding avoidance, overdominance at male-sterility loci, increased resource allocation to individual seeds by female plants, spatial structuring of populations, and populationlevel traits may also play important roles in the maintenance of this sexual system (van Damme, 1984; Gouyon and Couvet, 1987; Poot, 1997; Sakai et al., 1997; Dinnetz and Jerling, 1998; Delph, Bailey, and Marr, 1999; Graff, 1999). Furthermore, sex-related differences in components of female fitness other than fecundity-related ones are not as well documented. The relative scarcity of studies addressing gender-related variation in vegetative traits and physiology of gynodioecious species might indicate a real absence of dimorphism or just a low interest in these aspects due to the assumption that male reproductive function is not costly in plants. Recent studies have shown that this assumption is not always verified (Eckhart and Chapin, 1997; Eckhart and Seger, 1999), thus highlighting the relevance of searching for dimorphic traits other than fecundity-related ones in gynodioecious plants.

This paper reports the results of an investigation aimed at 
evaluating both vegetative and reproductive differences between female and hermaphrodite Daphne laureola (Thymelaeaceae) individuals that could help to explain the high frequency of female plants in natural populations of this species in southeastern Spain. We compared both vegetative (plant size, production of leaves, leaf size, leaf chemistry, and leaf growth) and reproductive parameters (fruit set and flower and fruit production). Hand-pollinations were also conducted to test for pollen compatibility in hermaphrodites and to evaluate the differences in fruit set and fruit characteristics between females and hermaphrodites (self- and cross-pollinated) as an estimate of early inbreeding depression. Possible differences in seedling emergence under field conditions were also investigated. Additionally, we surveyed the sex ratio of $D$. laureola populations along a broad elevational gradient in the study region, as an indirect way of assessing the potential role of ecological factors as determinants of gender-related fitness differences that could contribute to the maintenance of females in populations. The objectives of this paper thus were (1) to describe the main aspects of the reproductive biology of D. laureola; (2) to evaluate the magnitude of gender dimorphism in reproductive and vegetative parameters; (3) to estimate the magnitude of inbreeding depression up to the seedling emergence stage; and (4) to determine the sex ratio in natural populations and its possible correlates with ecological conditions.

\section{MATERIALS AND METHODS}

Study species-Daphne laureola L. (Thymelaeaceae) is a $0.5-1.5 \mathrm{~m}$ tall, evergreen shrub that, in the Mediterranean region, is generally found in the understory of coniferous and mixed-montane forests. Branches exhibit strongly monopodial growth, and they elongate over several consecutive growing seasons without any secondary branching. Leaves occur only at the distal end of branches, where they form a well-defined rosette ("whorl" hereafter; see Alonso and Herrera, 1996, fig. 1, for a schematical representation of the plant). At our study sites in the Sierras de Cazorla-Segura-Las Villas (see below), lateral inflorescences are produced in late autumn on shoots of the previous year (Nieto Feliner, 1996, fig. 2), and flowering takes place from late January to April. Like other species in its genus (Kikuzawa, 1989), D. laureola is gynodioecious, with populations consisting of a mixture of hermaphrodite and female individuals (Nieto Feliner, 1997). Female flowers have vestigial stamens that do not produce pollen and have shorter corolla tubes (mean $\pm 1 \mathrm{SD}=4.9 \pm 0.45 \mathrm{~mm}, N=45$ flowers; this notation will be used throughout this paper unless otherwise noted) than perfect, hermaphrodite ones $(8.1 \pm 0.92 \mathrm{~mm}, N=56)$. Pollination is effected by both diurnal (bees in the families Andrenidae, Megachilidae and Apidae; nitidulid beetles) and nocturnal (several species of noctuid moths) insects. Fruits are single-seeded, black drupes that ripen in early June. At our study region, most fruits are ordinarily preyed upon by seed-eating mice and birds before ripening (Obeso, 1985; Hulme, 1992). A similarly high incidence of mouse predation on developing fruits has been reported by Kikuzawa (1989) for the closely related Daphne kamtchatica in Japan. Seed dispersal is accomplished by frugivorous passerine birds. No information is available on the mechanism of sex determination in this species. We did not find any indication of sex lability in marked plants during the course of this study.

Study sites and sex ratios-This study was carried out during 1995-2000 in the Natural Park of Sierras de Cazorla-Segura-Las Villas, a 214000-ha protected area in Jaén province, southeastern Spain (see Luque [1995] and Benavente [1996] for descriptions of the flora and vegetation of the region). During the flowering period of years 1996-2000, the proportions of female and hermaphrodite individuals were determined in $21 \mathrm{D}$. laureola populations widely distributed in the Park. Efforts were made to thoroughly sample the whole range of elevations and ecological conditions occupied by the species in the region. The two most distant populations were $\sim 60 \mathrm{~km}$ apart, and the

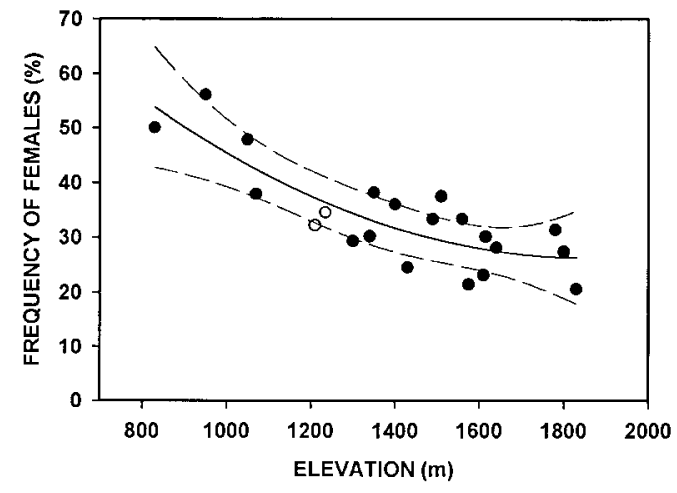

Fig. 1. Proportion of female individuals in 21 widely spaced populations of Daphne laureola located at different elevations within the Natural Park of Sierras de Cazorla-Segura-Las Villas, southeastern Spain. The two open symbols denote the position of the two populations where gender-related differences in vegetative and reproductive parameters were studied in detail (Cuevas Bermejas and Roblehondo). The continuous line is the quadratic regression curve fitted to the data $\left(R^{2}=0.69, F_{2,18}=20.31, P<0.0001\right)$, and the dashed lines indicate the $95 \%$ confidence intervals for the regression.

elevation of sampled populations ranged between 830 and $1830 \mathrm{~m}$. This range encompasses most of the actual elevational range of the species in the Park (750-1930 m, C. M. Herrera, unpublished data). At each site, we scored as many plants as possible for sexual morph (range $=23-147$ plants surveyed per population; $N=1737$ plants scored, all sites combined). Beyond a threshold size, all $D$. laureola plants flower every year, so we are confident that our sex ratio estimates adequately reflect the proportion of sexual morphs in the adult populations sampled.

Plant characterization-Two of the surveyed populations were intensively studied, located at Roblehondo (RH hereafter, $1235 \mathrm{~m}$ elevation) and Cuevas Bermejas (CB, $1210 \mathrm{~m}$ ), nearly $2 \mathrm{~km}$ apart. Detailed study of plant characteristics (plant size, physical and chemical characteristics of leaves, and reproductive parameters) were conducted on 28 marked shrubs at each of these sites during 1995-1996. Additional aspects of the plants' reproductive biology were studied at RH in 1998. The RH and CB populations are intermediate with respect to both elevation and proportion of females (Fig. 1). Furthermore, the species composition of their local plant communities (see Alonso and Herrera, 1996) may be regarded as fully representative of sites with $D$. laureola populations.

The height of the tallest branch ("plant height" hereafter) and the total number of leaf whorls ("number of whorls" hereafter) were used to characterize plant size. Several variables were measured on each marked plant in 1995 that described different components of its reproductive output. The proportion of whorls bearing inflorescences was determined for each marked plant. The number of inflorescences per whorl was determined for a subsample of whorls (22 and 27 whorls per plant, on average, in CB and RH, respectively), and the number of flowers per inflorescence was assessed in a sample of five inflorescences per plant. Estimates of flower production per whorl were obtained from these figures. Fruit set (percentage flowers setting fruit) was determined at two stages, by combining information on flower production with counts of developing (April) and nearly ripe (May) fruits. Potential fruit predators were not excluded from developing infructescences, hence our late fruit-set estimates may partly reflect the removal of an undetermined number of fruits by predators.

Initial leaf expansion rate was estimated by measuring the longest leaf in five whorls from each marked plant at the beginning of March, when leaves started to develop (mean length $=11.6 \mathrm{~mm}$ ) and again 1 mo later (mean length $=52.8 \mathrm{~mm}$ ). To characterize them physically and chemically, leaves were collected from each marked plant in April (young, expanding leaves) and June (mature, final-sized leaves) 1996. On each sampling occasion, 4-5 leaf whorls were randomly selected on each marked plant, and 3-4 intact leaves were collected from each whorl, up to a total of 18 leaves per plant. 
Leaves were cut with scissors, placed in sealed plastic bags, and brought to the laboratory in a portable refrigerator to minimize water loss. Leaves were weighed individually, pressed, dried at $45^{\circ} \mathrm{C}$ to a constant mass, and then reweighed. Leaves were then photocopied, their images digitized using a scanner, and their areas measured. Percentage water content was computed for individual leaves as $100 \times$ (fresh mass - dry mass)/fresh mass. For the purpose of this paper, plant means were obtained for all the leaves from the same sampling occasion, and the two resulting values (for April and June samples) were then averaged to obtain a single figure for each plant. It must be noted, however, that results of analyses conducted separately on leaves from the two collection dates were similar.

After measurement, all leaves from the same plant and collection date were pooled into a single sample and ground in a coffee mill to prepare samples for chemical analyses. Two samples were thus available per plant (April and June), which were analyzed for $\mathrm{N}, \mathrm{P}, \mathrm{K}, \mathrm{Mg}, \mathrm{Ca}, \mathrm{Cu}, \mathrm{Fe}, \mathrm{Mn}$, and $\mathrm{Zn}$ content. Analyses were performed at the laboratories of the Instituto de Recursos Naturales y Agrobiología, CSIC, Sevilla. Total N content was determined by the Kjeldahl method by using a Technicon BD-40 Digestor Block for mineralization and AutoAnalyzer II for determination (Technicon Instrument Corp., Tarrytown, New York, USA). Potassium and Na content were determined by flame spectrophotometry, vanadate-molibdate spectrophotometry was used for $\mathrm{P}$ determination, and atomic spectrophotometry for the other elements. As for leaf physical characteristics, element concentrations obtained from the two sampling occasions were also averaged to obtain a single figure for each individual plant.

Experimental pollinations - Self-compatibility in hermaphrodites and differences in fruit set between the two sexes were experimentally tested in 1998 at $\mathrm{RH}$ on five hermaphrodite and three female individuals. In hermaphrodites, experimental pollination treatments were applied according to a randomized complete block design (plants treated as blocks) with two different factors, namely emasculation (emasculated vs. nonemasculated flowers) and pollen origin (self vs. cross pollen). A control group of flowers was also set consisting of both emasculated and nonemasculated flowers that did not receive pollen. In females, flowers were only assigned to either pollinated or nonpollinated treatments. Two weeks before experimental pollen addition, when flowers were still closed and anthers were not yet mature, all experimental flowers were laterally opened by cutting the corolla with a scalpel, and anthers of those flowers assigned to emasculation treatment were removed. A second set of unpollinated, control flowers was also marked and left intact to test for the possible effects of lateral cutting of flowers on fruit set. No significant differences in fruit set were found between the two types of control flowers (cut and uncut), thus only the data from control flowers that were laterally cut will be considered here.

In hermaphrodites, self-pollination was performed by collecting pollen from different flowers on the same individual using a fine brush and applying this pollen to the stigma of experimental flowers. Cross-pollination was performed by collecting mature anthers from several individuals in the same population that were not used as pollen receptors. The pollen from these anthers was thoroughly mixed into a small box and transferred to stigmas with a brush. The same method was used in the pollination treatment of female flowers. Thus, all outcross treatments received the same batch of mixed pollen. Different brushes were used for different individuals and treatments. All available flowers in the same inflorescence received the same treatment and only two or three inflorescences were treated within a single leaf whorl. After pollination, both control and treated flowers were bagged to preclude access of pollinators and protect flowers and developing fruits from predation. In addition, some unmanipulated hermaphrodite flowers were bagged to test for spontaneous self-fecundity. Untreated flowers on experimental plants were also marked and left exposed to natural pollination to assess fruit set under natural conditions. Unfortunately, however, fruit and seed predators destroyed most developing fruits in these unbagged branches before ripening, and presentation of these results will be omitted.

Number of fruits produced after pollination treatments were counted in April ("early" determination, fruits still unripe) and mid-June ("final" determination, ripe fruits). All ripe fruits were collected and the fresh mass of pulp and seeds was determined separately. Ripe fruits produced by experimental plants on nonexperimental branches, and thus resulting from natural pollination, were also collected. All the seeds obtained from the ripe fruits of experimental plants were sown in the field in the RH area in December 1998, according to a randomized complete block design $(N=15$ blocks $)$. Seeds were classed into five categories, namely selfed-hermaphrodite $(N=69$ seeds), crossed-hermaphrodite $(N=59)$, crossed-female $(N=93)$, unbaggedhermaphrodite $(N=92)$, and bagged-hermaphrodite $(N=92)$. Selfed-hermaphrodite comprised seeds from both emasculated and nonemasculated selfpollinations. Similarly, crossed-hermaphrodite comprised seeds from both emasculated and nonemasculated flowers. Unbagged-hermaphrodite consisted of seeds from flowers naturally pollinated. Bagged-hermaphrodite seeds came from nontreated inflorescences in the same stems where other inflorescences had been treated, thus presumably resulting from self-pollination accidentally induced by stem manipulation (see Results). We were not able to test for maternal effects due to small sample size and, thus, all seeds from the same treatment were pooled and haphazardly distributed among blocks. Seeds from the five different categories were sown in different rows in each block $(40 \times$ $40 \mathrm{~cm}$ plots), with the order randomized within blocks. Plots were protected from seed predators and herbivores with wire-net boxes. Sites were visited regularly from January 1999 until June 2000 to record seedling emergence.

Data analyses - Procedures used for statistical comparisons between female and hermaphrodite individuals depended on whether there were replicate measurements per plant or not. For variables consisting of single data points per plant (e.g., plant size, physical and chemical properties of leaves, leaf growth), comparisons between the two genders were performed using nonparametric Kruskal-Wallis analysis of variance when data depart from normality (SAS procedure NPAR1WAY) and Student $t$ tests if data are normally distributed (SAS procedure TTEST) (all statistical analyses were performed using procedures in the SAS Package; SAS, 1989). Generalized linear mixed models (Littell et al., 1996) are used when true within-plant replicates of count or proportion data are available for individual plants (e.g., number of inflorescences per whorl, number of flowers per inflorescence, fruit set). Plant sex (female vs. hermaphrodite) was the only fixed factor in these models, while plant individual and population $(\mathrm{CB}$ and $\mathrm{RH})$ were treated as random factors. Computations were performed using SAS Macro program GLIMMIX (Littell et al., 1996), which uses SAS Procedure MIXED (SAS, 1996). Model-adjusted means and confidence intervals for female and hermaphrodite plants were obtained with the LSMEANS statement of Procedure MIXED. For further details and examples of the application of generalized linear mixed methods to plant reproduction studies, see, e.g., Herrera (2000a).

Comparisons among hand-pollination treatments were based on data of ripe fruit set (i.e., the proportion of flowers eventually producing a ripe fruit). Hand-pollination treatments (emasculation and pollination) were considered as fixed factors and their effects evaluated using planned contrasts in generalized linear models (see, e.g., Winer, 1971; Procedure GENMOD).

Estimates of seedling emergence rate (= seedlings emerged/seeds sown) were analyzed by fitting generalized linear models to the data using SAS procedure GENMOD. Rate of emergence was modeled as a binomial process using logits. Planned contrasts between self- and outcross-pollination in hermaphrodites and between female and self-, outcross-, and naturally pollinated hermaphrodites were tested.

\section{RESULTS}

Sex ratio-The frequency of female plants ranged between 20.6 and $56.1 \%$ in the $21 \mathrm{D}$. laureola populations surveyed. Variation among populations in the proportions of the two sexes was statistically significant $\left(\chi^{2}=51.04, \mathrm{df}=20, P<\right.$ 0.0001 ) and predictably related to changes in elevation. The proportion of female individuals decreased significantly with increasing site elevation (Fig. 1). The elevational trend departed from linearity, with the rate of decline in female frequency being steepest at the lowest elevations and tending to decelerate at higher elevations. 
TABLE 1. Reproductive parameters of female and hermaphrodite Daphne laureola plants.

\begin{tabular}{|c|c|c|c|c|c|}
\hline \multirow[b]{2}{*}{ Variable } & \multicolumn{2}{|c|}{ Plant sex } & \multirow[b]{2}{*}{$t$} & \multirow[b]{2}{*}{$F$} & \multirow[b]{2}{*}{$P$} \\
\hline & Female & Hermaphrodite & & & \\
\hline Proportion of whorls flowering $(\%)^{\mathrm{a}}$ & $68.8 \pm 26.4$ & $74.2 \pm 21.0$ & 0.82 & & 0.41 \\
\hline No. inflorescences per flowering whorl ${ }^{\mathrm{b}}$ & $5.0(4.4-5.8)$ & $4.8(4.4-5.3)$ & & 0.20 & 0.65 \\
\hline No. flowers per inflorescence $b$ & $7.2(6.4-7.9)$ & $7.4(6.8-8.0)$ & & 0.37 & 0.54 \\
\hline \multicolumn{6}{|l|}{ Fruit set $(\% \text { of flowers })^{b}$} \\
\hline "Early" (April) & $23.8(12.0-41.7)$ & $32.5(19.6-48.8)$ & & 1.44 & 0.23 \\
\hline "Final" (May) & $13.8(7.5-24.1)$ & $19.9(14.0-27.5)$ & & 1.16 & 0.28 \\
\hline
\end{tabular}

${ }^{a}$ Comparison performed using Student's $t$ test, the two populations combined ( $N=17$ female and 40 hermaphrodite plants). Values shown are means $\pm 1 \mathrm{SD}$.

${ }^{\mathrm{b}}$ Comparisons performed using generalized linear mixed models. All models fitted were similar and included plant sex as a fixed effect and population $(N=2$ sites) and plant nested within population as random effects. Model-adjusted means and confidence limits (in parentheses) obtained with the LSMEANS statement in Procedure MIXED. See text for further details.

Plant size-At the two intensively studied CB and RH populations, hermaphrodite and female plants did not differ significantly in either height $\left(\chi^{2}=0.10\right.$ and $0.45, \mathrm{df}=1, P=$ 0.75 and 0.50 , for $\mathrm{CB}$ and $\mathrm{RH}$, respectively; Kruskal-Wallis ANOVA) or number of whorls $\left(\chi^{2}=0.01\right.$ and $0.001, \mathrm{df}=1$, $P=0.94$ and 0.98 , for $\mathrm{CB}$ and $\mathrm{RH}$ sites, respectively).

Reproductive parameters-In $\mathrm{CB}$ and $\mathrm{RH}$, female and hermaphrodite plants of $D$. laureola did not differ significantly in any of the reproductive parameters considered (Table 1). Plants of the two sexes were statistically indistinguishable with regard to the proportion of whorls bearing inflorescences, mean number of inflorescences per flowering whorl, mean number of flowers per inflorescence, and percentage fruit set (for both "early" and "final" determinations). Estimates of the total number of fruits produced per plant may be obtained by combining multiplicatively the latter three parameters with values for mean number of whorls per plant (69.9 and 59.0 whorls/ plant for females and hermaphrodites, respectively) and proportion of whorls bearing flowers (Table 1). Figures thus obtained were 239 and 309 fruits/plant for females and hermaphrodites, respectively.

\section{Leaf characteristics -Daphne laureola plants from the CB}

TABle 2. Physical and chemical characteristics (means \pm 1 SD) of Daphne laureola leaves, Cuevas Bermejas and Roblehondo populations combined. Each shrub was characterized by averaging the values from samples of expanding and mature leaves.

\begin{tabular}{lcclll}
\hline \hline & \multicolumn{2}{c}{ Plant sex } & & \multicolumn{2}{c}{ Difference } \\
\cline { 2 - 3 } \cline { 5 - 6 } \multicolumn{1}{c}{ Variable } & $\begin{array}{c}\text { Female } \\
(N=17 \text { plants })\end{array}$ & $\begin{array}{c}\text { Hermaphrodite } \\
(N=40 \text { plants })\end{array}$ & & $t$ & $P$ \\
\hline Leaf characteristics & & & & & \\
Area $\left(\mathrm{mm}^{2}\right)$ & $959.1 \pm 167.6$ & $982.7 \pm 179.7$ & & 0.46 & 0.65 \\
Fresh mass $(\mathrm{mg})$ & $310.2 \pm 67.1$ & $321.0 \pm 77.5$ & & 0.50 & 0.62 \\
Dry mass $(\mathrm{mg})$ & $59.0 \pm 14.0$ & $60.7 \pm 14.3$ & & 0.42 & 0.68 \\
Water content $(\%)$ & $80.7 \pm 1.6$ & $80.7 \pm 1.8$ & & 0.03 & 0.98 \\
Chemical elements & & & & & \\
$\mathrm{N}(\mathrm{g} / \mathrm{kg})$ & $24.95 \pm 2.73$ & $24.96 \pm 2.45$ & & 0.015 & 0.99 \\
$\mathrm{P}(\mathrm{g} / \mathrm{kg})$ & $2.75 \pm 0.32$ & $2.80 \pm 0.58$ & & 0.36 & 0.72 \\
$\mathrm{~K}(\mathrm{~g} / \mathrm{kg})$ & $22.78 \pm 2.88$ & $22.95 \pm 2.14$ & & 0.26 & 0.80 \\
$\mathrm{Ca}(\mathrm{g} / \mathrm{kg})$ & $6.01 \pm 1.43$ & $5.80 \pm 1.44$ & & 0.51 & 0.61 \\
$\mathrm{Mg}(\mathrm{g} / \mathrm{kg})$ & $1.91 \pm 0.46$ & $2.00 \pm 0.42$ & & 0.72 & 0.47 \\
$\mathrm{Na}(\mathrm{g} / \mathrm{kg})$ & $0.16 \pm 0.08$ & $0.17 \pm 0.08$ & & 0.22 & 0.83 \\
$\mathrm{Zn}(\mathrm{mg} / \mathrm{kg})$ & $61.2 \pm 9.5$ & $64.0 \pm 9.5$ & & 1.01 & 0.32 \\
$\mathrm{Fe}(\mathrm{mg} / \mathrm{kg})$ & $57.4 \pm 8.6$ & $60.5 \pm 12.5$ & & 0.91 & 0.37 \\
$\mathrm{Mn}(\mathrm{mg} / \mathrm{kg})$ & $42.2 \pm 6.8$ & $42.8 \pm 9.8$ & & 0.22 & 0.83 \\
$\mathrm{Cu}(\mathrm{mg} / \mathrm{kg})$ & $9.47 \pm 1.46$ & $10.66 \pm 3.22$ & & 1.92 & 0.06 \\
\hline
\end{tabular}

and $\mathrm{RH}$ populations did not differ significantly with regard to either physical or chemical characteristics of leaves, hence data from the two sites were pooled into a single sample for the analyses reported in this section.

Female and hermaphrodite plants were statistically indistinguishable with regard to the physical characteristics of their leaves (Table 2). Univariate comparisons failed to detect any significant differences in leaf area, fresh and dry mass, or percentage water content of leaves. Difference between sexes in leaf physical characteristics was likewise nonsignificant when the four variables considered were analyzed simultaneously by means of a multivariate analysis of variance (Wilk's $\lambda=$ 0.931, df $=6,50, P=0.72$ ).

In univariate comparisons, female and hermaphrodite plants did not differ significantly in the content of any of the individual elements considered (Table 2). The difference between the sexes was likewise nonsignificant when data from all mineral elements were analyzed simultaneously using a multivariate analysis of variance (Wilk's $\lambda=0.925, \mathrm{df}=10,46, P=$ 0.95).

Leaf growth and production-There were no significant differences among sexes in initial leaf expansion rate in either $\mathrm{CB}$ or $\mathrm{RH}$ sites. In $\mathrm{CB}$, mean leaf elongation was $43.7 \pm 5.3$ $\mathrm{mm} / \mathrm{mo}$ and $44.6 \pm 8.3 \mathrm{~mm} / \mathrm{mo}$ for females and hermaphrodites, respectively $(t=0.27, \mathrm{df}=26, P=0.78)$. Corresponding figures for $\mathrm{RH}$ were $37.9 \pm 8.8 \mathrm{~mm} / \mathrm{mo}$ and $37.0 \pm 9.8$ $\mathrm{mm} / \mathrm{mo}$ for females and hermaphrodites, respectively, and differences between sexes were likewise nonsignificant $(t=0.23$, $\mathrm{df}=25, P=0.81)$. Moreover, female and hermaphrodite individuals did not differ in the mean number of leaves produced per whorl and season (12.3 and 12.6 leaves for females and hermaphrodites, respectively; Wald's $\chi^{2}=0.27, \mathrm{df}=1$, $P=0.6)$.

Experimental pollinations-Results of the different handpollination experimental treatments are summarized in Table 3. Hermaphrodite flowers of $D$. laureola are self-compatible. When pollen from different flowers of the same plant was applied to stigmas, $33.7 \%$ of emasculated and $18.2 \%$ of nonemasculated hermaphrodite flowers produced ripe fruits (Table 3). However, a pollen vector was required for fertilization, since none of the unmanipulated flowers left inside bags set any fruit ("Control" category in Table 3).

Fruit set of experimentally pollinated flowers was significantly higher than that of nonpollinated flowers for both female (Table 3, contrast A) and hermaphrodite (Table 3, con- 
TABLE 3. Pollination treatments applied to flowers of female (Fem.) and hermaphrodite (Her.) Daphne laureola individuals, resulting fruit set, and summary of results for planned linear contrasts testing for the effects of sex, emasculation and pollination treatment of fruit set. Linear contrast coefficients are shown to favor interpretation and repeatability of the analyses that correspond to the following comparisons: A, pollen addition in females; B, pollen addition in hermaphrodites; C, cross-pollination in hermaphrodites vs. pollen addition in females; D, self-pollination in hermaphrodites vs. pollen addition in females; E, pollen saturation in the stigma in cross-pollinated hermaphrodites; F, pollen saturation in the stigma in self-pollinated hermaphrodites; G, self- and cross-pollination in hermaphrodites when emasculated; $\mathrm{H}$, self- and cross-pollination in hermaphrodites when nonemasculated. Statistically significant and near-significant $P$ values are shown in boldface type.

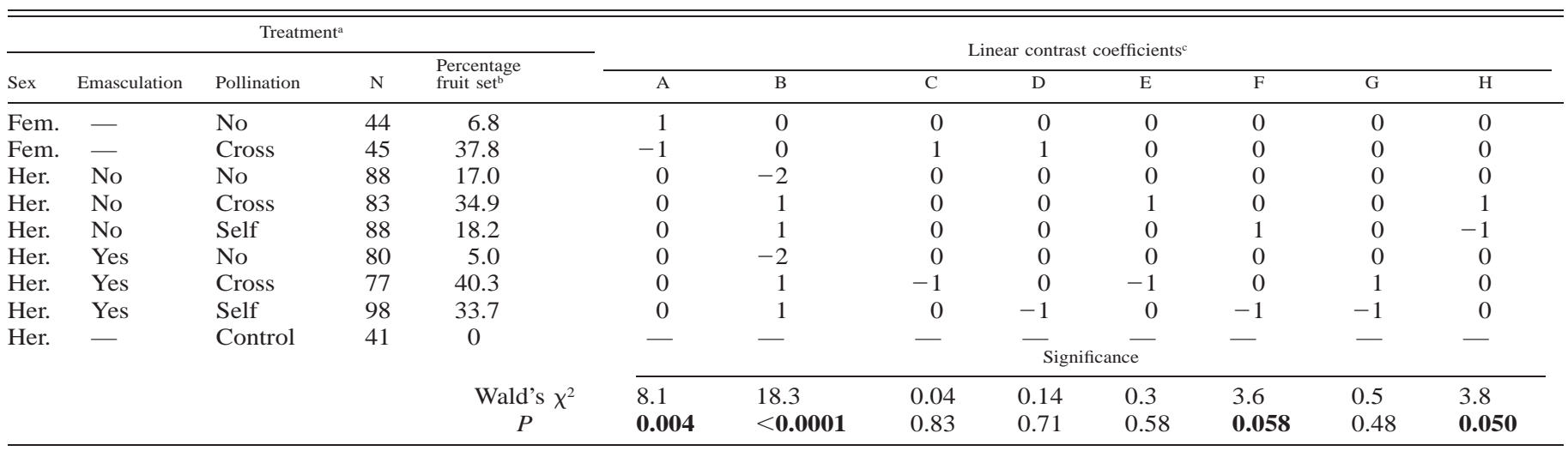

a Pollinators were excluded from all treatment categories. The "Control" category corresponds to untreated (i.e., corollas not cut laterally for manipulation) hermaphrodite flowers kept inside bags to test for spontaneous self-pollination and were excluded for further analyses. In all the other treatments, corollas were cut laterally regardless of whether they were subsequently emasculated or not (see METHODS). $N=$ number of flowers in each category.

${ }^{\mathrm{b}}$ Percentage flowers producing ripe fruits.

c All contrasts are based on $\mathrm{df}=1,87$. Wald's $\chi^{2}$ and significance of differences in ripe fruit set among contrasted treatments are also shown.

trast B) flowers. Fruit set increased, on average, from $6 \pm$ $15 \%$ to $36 \pm 15 \%$ for females and from $11 \pm 15 \%$ to $31 \pm$ $25 \%$ for hermaphrodites (model-adjusted means $\pm 1 \mathrm{SE}$ ). The few fruits produced by unpollinated flowers can be attributed to accidental stigma contamination during manipulation of the stems.

Fruit set of female flowers did not differ significantly from that of either cross- or self-pollinated hermaphrodite flowers (Table 3, contrasts C and D, respectively). In hermaphrodites, there were complex effects of both pollen quality and pollen saturation on fruit set (Table 3, contrasts E-H). Fruit set of cross-pollinated flowers was higher than that of self-pollinated flowers for both emasculated and nonemasculated flowers. The difference, however, was only marginally significant for nonemasculated flowers (Table 3, contrast $\mathrm{H}$ ) and nonsignificant

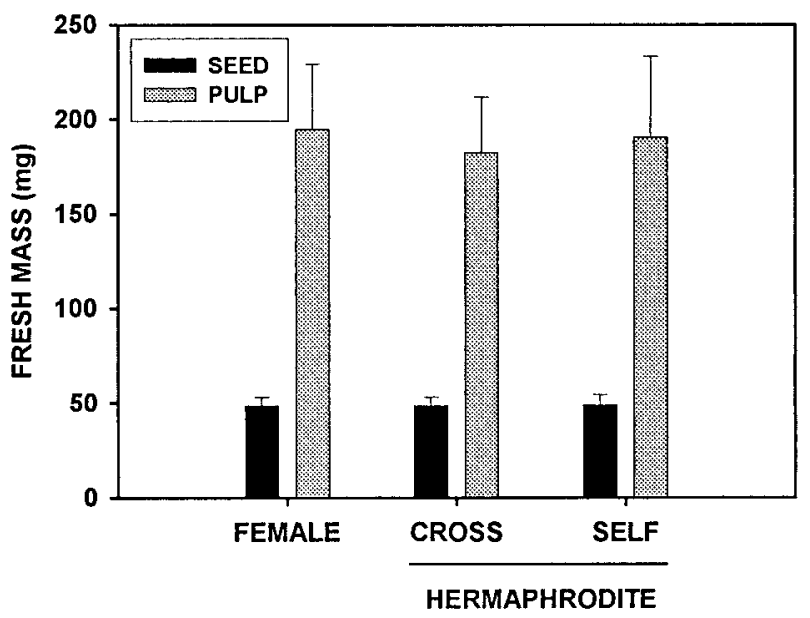

Fig. 2. Mean seed and pulp fresh mass from Daphne laureola fruits obtained from experimental hand-pollinations. Vertical segments denote $+1 \mathrm{SE}$. for emasculated flowers (Table 3, contrast G). The slight fruit set advantage of cross- over self-pollinated flowers was not due to differences in fruit initiation rate, but rather to significant differences in fruit abortion rates. Fruit abortion could be confidently estimated as the fraction of initiated fruits (assessed by the "early" fruit set determination) that eventually failed to ripen, since experimental flowers and developing fruits were protected from fruit predation. Fruit abortion rate was significantly higher in self-pollinated $(44 \pm 42 \%)$ than in cross-pollinated $(10 \pm 23 \%)$ hermaphrodite flowers (Wald's $\chi^{2}$ $=5.8 \mathrm{df}=1, P=0.016)$. Proportion of fruit abortion in female pollinated flowers was intermediate $(22 \pm 24 \%)$ and not significantly different from either self- or cross-pollinated hermaphrodite flowers.

Differences in fruit set between emasculated and nonemasculated hermaphrodite flowers were marginally significant for the self-pollen treatment (Table 3, contrast F), with emasculated flowers exhibiting a higher fruit set than nonemasculated ones. There was no significant difference in fruit set among emasculated and nonemasculated flowers (Table 3, contrast E).

Fruit and seed traits-There was no effect of pollination treatment or plant sex on fruit and seed traits. Mean mass of seeds from female flowers was similar to that of both selfpollinated (Wald's $\chi^{2}=0.11$, df $=1, P=0.74$ ) and crosspollinated (Wald's $\chi^{2}=0.0006, \mathrm{df}=1, P=0.98$ ) seeds from hermaphrodites (Fig. 2). The same was true for pulp mass (Fig. 2). Furthermore, seeds produced from self- and cross-pollination in hermaphrodites did not differ in mass either when flowers had been emasculated (Wald's $\chi^{2}=0.04$, df $=1, P$ $=0.84$ ) or when they had not (Wald's $\chi^{2}=1.70$, df $=1, P$ $=0.19$ ).

Fruits from naturally pollinated flowers collected from the same experimental female and hermaphrodite individuals were also similar in mean seed mass (Wald's $\chi^{2}=0.99$, $\mathrm{df}=1, P$ 
$=0.32$ ) and pulp mass (Wald's $\chi^{2}=0.07, \mathrm{df}=1, P=0.80$ ). It must be noted that, within sexes, individual plants did differ significantly for both seed (Wald's $\chi^{2}=250.0$, df $=7, P<<$ 0.0001 ) and pulp (Wald's $\chi^{2}=138.7$, df $=7, P<<0.0001$ ) mass. This indicates that individual variability in fruit traits effectively existed in the population, although it was unrelated to plant sex.

Seedling emergence-Only $23 \%$ of the seeds sown in December $1998(N=405)$ produced a seedling during the first two seasons after sowing. The vast majority of these $(21.7 \%)$ germinated in the second spring after sowing (2000). Emergence during the first spring (1999) was negligible, probably due to a combination of seed dormancy and extremely low rainfall.

The difference in emergence rate between seeds from self$(14.5 \%)$ and cross-pollinated $(18.6 \%)$ hermaphrodite flowers was not statistically significant (Wald's $\chi^{2}=0.40$, df $=1, P$ $=0.53)$. There was a trend for seeds from female flowers to have a higher emergence rate $(29.0 \%)$ than those from crosspollinated hermaphrodite flowers $(18.6 \%)$, but the difference did not reach statistical significance (Wald's $\chi^{2}=2.14$, df $=$ $1, P=0.14)$. Seeds from female plants, however, gave rise to significantly more seedlings than seeds from self-pollinated hermaphrodites flowers $(14.5 \%)$ (Wald's $\chi^{2}=4.93$, df $=1, P$ $=0.02)$. The difference in emergence rate between seeds from female and naturally pollinated hermaphrodite flowers $(26.1 \%)$ was not significant (Wald's $\chi^{2}=0.20$, df $=1, P=0.65$ ).

\section{DISCUSSION}

Female individuals were quite common in all the D. laureola populations surveyed in the Cazorla-Segura-Las Villas region. At some localities near the lower limit of the species' elevational range, they were as abundant or more than hermaphrodites. Nevertheless, little evidence of compensatory fitness advantage of female individuals was found in this study that could account for their generalized abundance in the region. Adult reproductive shrubs of both sexes did not differ significantly in any of the vegetative and reproductive parameters examined. Seed set and seed size of hand-pollinated female flowers, cross-pollinated hermaphrodites, and self-pollinated hermaphrodites were similar, suggesting that inbreeding depression was unimportant at this early reproductive stage. No evidence of inbreeding depression was likewise found in the subsequent seedling emergence stage, as selfed and crossed seeds from hermaphrodites did not differ in the probability of giving rise to a seedling. There was, however, a significant advantage of female over selfed hermaphrodite seeds in terms of seedling emergence under field conditions.

Vegetative and reproductive parameters-The vegetative traits considered in this study could influence plant growth and survival, either directly through their effects on the photosynthetic surface available or indirectly by influencing the competitive ability of plants or their susceptibility to herbivores (Agren et al., 1999). Since D. laureola starts to produce leaves while flowering (Nieto Feliner, 1996), females could, in theory, reallocate the resources "saved" by virtue of their smaller and pollenless flowers to the production and growth of vegetative organs. The absence of differences between sexes in all vegetative parameters studied suggests that either the costs of flowers and of the male function are negligible in this species or that extra resources becoming available to females are mostly redirected to a better provisioning of fruits and seeds (Delph, Bailey, and Marr, 1999; but see below).

As regards natural reproduction, our findings for $D$. laureola contrast with those of Kikuzawa (1989) for the congeneric (and also gynodioecious) Daphne kamtchatica, where female plants had a significant fruit-set advantage over hermaphrodites. This absence of significant sexual dimorphism in fecundity-related components is infrequent among gynodioecious species (but see, e.g., Ågren and Willson, 1991; del Castillo, 1993; Jordano, 1993; Maki, 1996) and could be partly explained by the considerable variation existing among individuals of the same sex in all the reproductive parameters studied. Genotype or location effects may be more influential than sex on fecundity-related fitness components of individual shrubs (Ashman, 1992b; Mutikainen and Delph, 1998; Graff, 1999). Additionally, the similar fruit set of both sexes suggests that females were not pollen limited in the two study populations.

Consistency of the results obtained for the $\mathrm{CB}$ and $\mathrm{RH}$ populations suggests that the fecundity patterns observed are not just local phenomena. The absence of significant differences in fruit set of naturally pollinated flowers of individual plants between 1995 and 1998 (C. Alonso, personal observations) further suggests that individual differences exhibit at least a certain degree of temporal consistency across years. Nevertheless, D. laureola is a long-lived perennial (precise estimates are lacking, but longevity certainly exceeds $40 \mathrm{yr}$ in the RH site), and estimates of reproductive output of hermaphrodites and females based on long-term longitudinal data of marked individuals are required before the possibility that sexes actually differ in cumulative lifetime fecundity can be safely ruled out.

Hand-pollinations - Hand-pollinations conducted at the RH population revealed both self-compatibility of $D$. laureola hermaphrodites and a strict requirement of pollen vectors for fertilization. Kikuzawa (1989) suggested that flowers of $D$. kamtchatica are self-incompatible, but that suggestion was based on the absence of spontaneous self-pollination in bagged hermaphrodite flowers. As evidenced by our results with $D$. laureola, null spontaneous self-pollination does not necessarily imply self-incompatibility, and the claim of self-incompatibility in D. kamtchatica should be taken with caution until it is substantiated by controlled pollination of hermaphrodite flowers with self-pollen.

Self-incompatibility and (gyno)dioecy have been regarded as two alternative mechanisms to avoid selfing in natural populations (Freeman et al., 1993) and, in fact, self-incompatibility is uncommon among gynodioecious species (Kaul, 1988). The occurrence and rate of selfing in hermaphrodites must thus be considered critical parameters in the reproductive biology of gynodioecious plant species. The differences between the results of pollinations of emasculated and nonemasculated flowers with self and cross pollen suggest both the existence of clogging and pollen competition on the stigmas of intact (nonemasculated) D. laureola flowers and a higher siring quality of outcross pollen. Under conditions of excess pollen on the stigma, the prevalence of outcross pollen apparently may come about through preferential abortion of self-fertilized fruits and/or superiority of cross pollen in gametophytic competition (Lovett Doust, 1990; Shykoff, 1992), which will contribute to reduce the selfing rate of hermaphrodites' offspring under natural pollination. The nonsignificance of the differ- 
ence in fruit set between females and emasculated hermaphrodites (both for self and cross pollen, contrasts C and D in Table 3) suggest that the two sexes are inherently similar in potential fruit set after the deleterious effects of pollen clogging have been experimentally removed by emasculation. This suggests that in D. laureola, as in D. kamtchatica (Kikuzawa, 1989), stigma clogging of hermaphrodite flowers and the subsequent reduction in fruit set may be an important reproductive disadvantage of hermaphrodites in relation to females when there is no pollen limitation.

In the RH population, inbreeding depression up to and including the ripe fruit stage is probably negligible, as supported by (1) the absence of significant fruit set differences between self- and cross-pollinated emasculated hermaphrodite flowers; and (2) the similarity in seed size and pulp amount per fruit shown by comparisons between selfed and crossed hermaphrodite flowers and between hermaphrodites and females. This leads us to tentatively conclude that the maintenance of females in $D$. laureola is unlikely due to the disadvantages derived by hermaphrodite individuals from inbreeding, in terms of a reduction in the number of fruits and seeds produced or in aspects of fruit quality that could influence seed dispersal success (amount of pulp) or offspring establishment (seed size).

Seedling emergence-The low seedling emergence rates obtained under natural conditions had the undesirable consequence of reducing the statistical power of our analyses, but they probably represent a realistic characterization of selection at this critical life-cycle stage (e.g., Sakai et al., 1997; Herrera, 2000a, b). Differences in emergence rate of self- and crosspollinated seeds of hermaphrodites were weak and nonsignificant, thus again suggesting that inbreeding depression was not strong enough at this stage to show up in our rather limited seedling emergence data. As found in other gynodioecious species (Assouad et al., 1978; van Damme and van Delden, 1984), field emergence rate of seeds from female flowers was higher than that for seeds from self- or cross-pollinated hermaphrodite flowers, when the same pollen donors were used to experimentally pollinate females and hermaphrodites. In contrast, seeds from naturally pollinated flowers of the same hermaphrodite plants, and thus presumably sired by different pollen donors, had emergence rates quite similar to that of females. One possible explanation for this puzzling result is that the identity of pollen donors may be highly influential on the success of seeds from hermaphrodites, probably through nuclear-cytoplasmic incompatibilities (van Damme, 1984). An effect of this kind would again reduce the level of inbreeding of the hermaphrodites' offspring and help to explain the absence of differences in adult traits. In any case, the superior emergence of female seeds, when the identity of pollen donors is held constant, suggests a possible mechanism contributing to their persistence in populations if, as it seems likely, sex inheritance in D. laureola is nuclear-cytoplasmic and progenies of females are female-biased. Inbreeding depression in selfed progeny from hermaphrodites could still show up in later stages of the life cycle not considered here, such as in differences in establishment of emerged seedlings or survival to reproduction (Husband and Schemske, 1996).

Sex ratio-Variation of sex ratio with elevation suggests that establishment and maintenance of $D$. laureola females may be mediated by ecological factors. Females are most prev- alent at lower elevations, precisely where populations of $D$. laureola are scarcest, and each is made up of the fewest number of individuals. In Mediterranean areas, summer drought is one of the critical factors for plant recruitment (e.g., Escudero et al., 1999; Lloret, Casanovas, and Peñuelas, 1999), and drought is presumably most severe at lower altitudes with hotter summers. The observed elevational pattern in the frequency of female plants is thus consistent with available data from other gynodioecious species and theoretical predictions suggesting that females can more easily invade and be maintained in harsh environments (Ashman, 1999; and references therein). Recruitment certainly is a limiting stage in D. laureola reproduction, as supported by the observation that seedlings and juveniles are very rarely found in natural populations. It is possible that offspring of female plants will be particularly favored under more stressful conditions, when the advantages derived from higher heterozygosity are usually revealed (e.g., Dudash, 1990; Ashman, 1992a; del Castillo, 1998), thus explaining the higher abundance of females at lower altitudes. Further studies are needed, however, to ascertain the mechanisms behind the observed altitudinal variation in sex ratio. Several other factors, such as pollen limitation and selfing rates (Williams and Fenster, 1998), relative fruit production of females and hermaphrodites (Delph, 1990; Ashman, 1999), and seed predation and dispersal (Dinnetz and Jerling, 1998; Williams and Fenster, 1998) could vary with elevation and might induce changes in the relative fitnesses of the two sexes (e.g., Alatalo and Molau, 1995). Abiotic influences on sex expression (Koelewijn and van Damme, 1996) might also be involved in the elevational differences in sex ratio. In any case, the existence of a predictable elevational gradient in D. laureola sex ratio suggests at least that frequency of females is not merely determined by the sex inheritance genetic system (Gouyon and Couvet, 1987).

Conclusions-Male sterility is commonly determined by the interaction between nuclear and cytoplasmic genes that leads to a complex inheritance mode (Couvet, Bonnemaison, and Gouyon, 1986) and requires just a subtle fecundity advantage of females for polymorphism to be maintained in the population (Gouyon and Couvet, 1987). Natural selection operates in a transgenerational way in which both quantity (i.e., number of offspring) and quality (i.e., offspring viability) aspects are relevant. The nuclear-cytoplasmic inheritance of male sterility provides hermaphrodites an advantage with regard to quantity, but also makes females more efficient at transmitting quality phenotypes to the next generation. From an ecological perspective, differences in quantity-related aspects are easier to evaluate and, as stated in the beginning, many studies have looked for and found a fitness compensation in females that explained the maintenance of gynodioecy. We failed to find this quantitative compensation in D. laureola. The most common forms of female compensation (i.e., higher fecundity, vegetative outperformance, and avoidance of inbreeding) could not apparently explain the high proportions of female D. laureola individuals found in populations of the CazorlaSegura-Las Villas region. We should, thus, more carefully search in the future for offspring quality differences. For instance, a detailed study of natural pollination is needed to estimate the actual rates of pollen limitation and selfing at different elevations, and in different years within each population, since variability in weather conditions could differently modify the reproductive output of both sexes. Longer obser- 
vations of seedling emergence and survival are also required to confidently evaluate the role of inbreeding depression in the later stages of $D$. laureola life cycle. Determination of segregation of sexes in female and hermaphrodite offspring would be also useful (Couvet, Bonnemaison, and Gouyon, 1986). Studies are currently underway directly aimed at solving the paradox of a high proportion of females without any conspicuous fecundity compensation.

\section{LITERATURE CITED}

Ågren, J., K. Danell, T. ElmQvist, L. Ericson, and J. HJältén. 1999. Sexual dimorphism and biotic interactions. In M. A. Geber, T. E. Dawson, and L. F. Delph [eds.], Gender and sexual dimorphism in flowering plants, 217-246. Springer, Berlin, Germany.

- AND M. F. WILLSON. 1991. Gender variation and sexual differences in reproductive characters and seed production in gynodioecious Geranium maculatum. American Journal of Botany 78: 470-480.

Alatalo, J. M., and U. Molau. 1995. Effect of altitude on the sex ratio in populations of Silene acaulis (Caryophyllaceae). Nordic Journal of Botany 15: 251-256.

Alonso, C., AND C. M. HerRera. 1996. Variation in herbivory within and among plants of Daphne laureola (Thymelaeaceae): correlation with plant size and architecture. Journal of Ecology 84: 495-502.

Ashman, T. L. 1992a. Indirect costs of seed production within and between seasons in a gynodioecious species. Oecologia 92: 266-272.

. 1992b. The relative importance of inbreeding and maternal sex in determining progeny fitness in Sidalcea oregana ssp. spicata, a gynodioecious plant. Evolution 46: 1862-1874.

- 1994. Reproductive allocation in hermaphrodite and female plants of Sidalcea oregana ssp. spicata (Malvaceae) using four currencies. American Journal of Botany 81: 433-438.

- 1999. Determinants of sex allocation in a gynodioecious wild strawberry: implications for the evolution of dioecy and sexual dimorphism. Journal of Evolutionary Biology 12: 648-661.

$\longrightarrow$, AND M. STANTON. 1991. Seasonal variation in pollination dynamics of sexually dimorphic Sidalcea oregana ssp. spicata (Malvaceae). Ecology 72: 993-1003.

Assouad, M. W., B. Dommée, R. Lumaret, and G. Valdeyron. 1978. Reproductive capacities in the sexual forms of the gynodioecious species Thymus vulgaris L. Botanical Journal of the Linnean Society 77: 29-39.

Benavente, A. 1996. Catálogo de fanerógamas del Parque Natural de las Sierras de Cazorla, Segura y Las Villas. Taller de Ecología, Linares, Spain.

Couvet, D., F. Bonnemaison, And P. H. Gouyon. 1986. The maintenance of females among hermaphrodites: the importance of nuclear-cytoplasmic interactions. Heredity 57: 325-330.

Dawson, T. E., AND M. A. Geber. 1999. Dimorphism in physiology and morphology. In M. A. Geber, T. E. Dawson, and L. F. Delph [eds.], Gender and sexual dimorphism in flowering plants, 175-215. Springer, Berlin, Germany.

Del Castillo, R. F. 1993. Consequences of male sterility in Phacelia dubia. Evolutionary Trends in Plants 7: 15-22.

. 1998. Fitness consequences of maternal and non-maternal components of inbreeding in the gynodioecious Phacelia dubia. Evolution 52: $44-60$.

DeLPH, L. F. 1990. Sex-differential resource allocation patterns in the subdioecious shrub Hebe subalpina. Ecology 71: 1342-1351.

- 1993. Factors affecting intraplant variation in flowering and fruiting in the gynodioecious species Hebe subalpina. Journal of Ecology 81: 287-296.

- 1999. Sexual dimorphism in life history. In M. A. Geber, T. E. Dawson, and L. F. Delph [eds.], Gender and sexual dimorphism in flowering plants, 149-173. Springer, Berlin, Germany.

, M. F. BAILEY, AND D. L. MARR. 1999. Seed provisioning in gynodioecious Silene acaulis (Caryophyllaceae). American Journal of Botany 86: $140-144$

$\longrightarrow$, AND C. M. Lively. 1992. Pollinator visitation, floral display, and nectar production of the sexual morphs of a gynodioecious shrub. Oikos 63: 161-170.

- AND D. G. LLOYD. 1991. Environmental and genetic control of gender in the dimorphic shrub Hebe subalpina. Evolution 45: 1957-1964.
DinNetZ, P., AND L. JerLING. 1997. Gynodioecy in Plantago maritima L.; no compensation for loss of male function. Acta Botanica Neerlandica 46: $193-206$.

— AND — 1998. Spatial distribution of male sterility in Plantago maritima. Oikos 81: 255-265.

DudAsh, M. R. 1990. Relative fitness of selfed and outcrossed progeny in a self-compatible, protandrous species, Sabatia angularis L. (Gentianaceae): a comparison in three environments. Evolution 44: 1129-1139.

ECKHART, V. M., AND F. S. ChAPIN. 1997. Nutrient sensitivity of the cost of male function in gynodioecious Phacelia linearis (Hydrophyllaceae). American Journal of Botany 84: 1092-1098.

- AND J. SEgER. 1999. Phenological and developmental costs of male function in hermaphroditic plants. In T. O. Vuorisalo and P. K. Mutikainen [eds.], Life history evolution in plants, 195-213. Kluwer, Dordrecht, The Netherlands.

Escudero, A., R. C. Somolinos, J. M. Olano, And A. Rubio. 1999. Factors controlling the establishment of Helianthemum squamatum, an endemic gypsophile of semi-arid Spain. Journal of Ecology 87: 290-302.

Freeman, D. C., J. Lovett Doust, A. El-Keblawy, K. J. Miglia, and E. D. MCArthur. 1993. Sexual specialization and inbreeding avoidance in the evolution of dioecy. Botanical Review 63: 65-92.

Gouyon, P. H., AND D. Couvet. 1987. A conflict between the two sexes, females and hermaphrodites. In S. C. Stearns [ed.], The evolution of sex and its consequences, 245-261. Birkhäuser, Basel, Switzerland.

GrafF, A. 1999. Population sex structure and reproductive fitness in gynodioecious Sidalcea malviflora malviflora (Malvaceae). Evolution 53: $1714-1722$.

HeRmanutZ, L. A., AND D. J. InNES. 1994. Gender variation in Silene acaulis (Caryophyllaceae). Plant Systematics and Evolution 191: 69-81.

HERrERA, C. M. 2000a. Flower-to-seedling consequences of different pollination regimes in an insect-pollinated shrub. Ecology 81: 15-29.

. $2000 \mathrm{~b}$. Individual differences in progeny viability in Lavandula latifolia: a long-term field study. Ecology 81: 3036-3047.

Hulme, P. E. 1992. The ecology of a temperate plant in a Mediterranean environment: post-dispersal seed predation of Daphne laureola. In C. A. Thanos [ed.], Plant-animal interactions in Mediterranean-type ecosystems, 281-286. University of Athens, Athens, Greece.

Husband, B. C., AND D. C. Schemske. 1996. Evolution of the magnitude and timing of inbreeding depression in plants. Evolution 50: 54-70.

JoRdANO, P. 1993. Pollination biology of Prunus mahaleb L.: deferred consequences of gender variation for fecundity and seed size. Biological Journal of the Linnean Society 50: 65-84.

KAUL, M. L. H. 1988. Male sterility in higher plants. Springer, Berlin, Germany.

KiKUZAWA, K. 1989. Floral biology and evolution of gynodioecism in Daphne kamtchatica var. jezoensis. Oikos 56: 196-202.

KoElewisn, H. P., AND J. M. M. van DAmME. 1996. Gender variation, partial male sterility and labile sex expression in gynodioecious Plantago coronopus. New Phytologist 132: 67-76.

KoHn, J. R. 1989. Sex ratio, seed production, biomass allocation, and the cost of male function in Cucurbita foetidissima HBK (Cucurbitaceae). Evolution 43: 1424-1434.

Krohne, D. T., I. BAKer, AND H. G. BAKer. 1980. The maintenance of the gynodioecious breeding system in Plantago lanceolata L. American Midland Naturalist 103: 269-279.

LEWIS, D. 1941. Male sterility in natural populations of hermaphrodite plants. New Phytologist 40: 56-63.

Littell, R. C., G. A. Milliken, W. W. Stroup, and R. D. Wolfinger. 1996. SAS system for mixed models. SAS Institute, Cary, North Carolina.

Lloret, F., C. Casanovas, and J. Peñuelas. 1999. Seedling survival of Mediterranean shrubland species in relation to root : shoot ratio, seed size and water and nitrogen use. Functional Ecology 13: 210-216.

Lloyd, D. G. 1976. The transmission of genes via pollen and ovules in gynodiocious angiosperms. Theoretical Population Biology 9: 299-316.

LovetT Doust, J. 1990. Botany agonistes: on phytocentrism and plant sociobiology. Evolutionary Trends in Plants 4: 121-133.

LuQue, P. 1995. Mapa de vegetación del Parque Natural de las Sierras de Cazorla, Segura y Las Villas. Junta de Andalucía, Consejería de Medio Ambiente, Sevilla, Spain.

MAKI, M. 1996. Differences in plant size and flower production between hermaphrodites and females of two gynodioecious Chionographis (Liliaceae). Canadian Journal of Botany 74: 150-153. 
Mutikainen, P., AND L. F. Delph. 1998. Inbreeding depression in gynodioecious Lobelia siphilitica: among-family differences override betweenmorph differences. Evolution 52: 1572-1582.

Nieto Feliner, G. 1996. Growth-form and intraspecific taxonomy in western Mediterranean Daphne (Thymelaeaceae). Israel Journal of Plant Sciences 44: 369-379.

1997. Thymelaeaceae. In S. Castroviejo, C. Aedo, C. Benedí, M. Laínz, F. Muñoz Garmendia, G. Nieto Feliner, and J. Paiva [eds.], Flora Iberica, vol. VIII, Haloragaceae-Euphorbiaceae, 32-69. Real Jardín Botánico, CSIC, Madrid, Spain.

Obeso, J. R. 1985. Comunidades de pájaros y frugivorismo en altitudes medias de la Sierra de Cazorla. Ph.D. dissertation, University of Oviedo, Oviedo, Spain.

Poot, P. 1997. Reproductive allocation and resource compensation in malesterile and hermaphroditic plants of Plantago laceolata (Plantaginaceae). American Journal of Botany 84: 1256-1265.

Sakai, A. K., S. G. Weller, M. Chen, S. Chou, and C. Tasanont. 1997. Evolution of gynodioecy and maintenance of females: the role of inbreeding depression, outcrossing rates, and resource allocation in Schiedea adamantis (Caryopyllaceae). Evolution 51: 724-736.

SAS. 1989. SAS/STAT user's guide, version 6, 4th ed. SAS Institute, Cary, North Carolina, USA.

. 1996. SAS/STAT software: changes and enhancements through Release 6.11. SAS Institute, Cary, North Carolina, USA.

ShyKofF, J. A. 1988. Maintenance of gynodioecy in Silene acaulis (Caryophyllaceae): stage-specific fecundity and viability selection. American Journal of Botany 75: 844-850.
1992. Sex polymorphism in Silene acaulis (Caryophyllaceae) and the possible role of sexual selection in maintaining females. American Journal of Botany 79: 138-143.

Slade, A. J., AND M. J. Hutchings. 1989. Within- and between-population variation in ramet behaviour in the gynodioecious clonal herb, Glechoma hederacea (Labiatae). Canadian Journal of Botany 67: 633-639.

Stevens, D. P. 1988. On the gynodioecious polymorphism in Saxifraga granulata L. (Saxifragaceae). Biological Journal of the Linnean Society 35: 15-28.

UNO, G. E. 1982. Comparative reproductive biology of hermaphroditic and male-sterile Iris douglasiana Herb. (Iridaceae). American Journal of Botany 69: 818-823.

VAN DAmme, J. M. M. 1984. Gynodioecy in Plantago lanceolata L. III. Sexual reproduction and maintenance of male steriles. Heredity 52: 77 93.

, AND W. VAn Delden. 1984. Gynodioecy in Plantago lanceolata L. IV. Fitness components of sex types in different life cycle stages. Evolution 38: 1326-1336.

WeBв, C. J. 1976. Flowering periods in the gynodioecious species Gingidia decipiens (Umbelliferae). New Zealand Journal of Botany 14: 207-210.

Williams, H. L., AND C. B. Fenster. 1998. Ecological and genetic factors contributing to the low frequency of male sterility in Chamaecrista fasciculata (Fabaceae). American Journal of Botany 85: 1243-1250.

Winer, B. J. 1971. Statistical principles in experimental design, 2nd ed. McGraw-Hill, New York, New York, USA

Wolfe, L. M., AND A. ShmidA. 1997. The ecology of sex expression in a gynodioecious Israeli desert shrub (Ochradenus baccatus). Ecology 78: 101-110. 